\title{
Research on the Countermeasures of Tourism Burst News in the Self-Media Environment
}

\author{
Lin Yang ${ }^{1, a}$ \\ ${ }^{1}$ Haikou College of Economics, Haikou, Hainan, China, 570100 \\ ${ }^{\mathrm{a}}$ email,
}

Keywords: Self-Media, Travel, Sudden

\begin{abstract}
As our country's economy continues to progress and people's living standards continue to improve, people are increasingly concerned about the tourism industry. Because of the over-fast development of tourism industry, there has been more and more problem of tourism disputes in the development process. Now, due to the continuous progress of science and technology, Internet technology continues to improve, making the speed of information transmission is constantly accelerating and it makes any problems are very fast spread. This has a certain impact on the tourism industry. In the current media environment, the tourism industry frequently unexpected news events, allowing visitors through the media quickly spread the event and passed out, the fight against the tourism industry is very large, and this article is about the news of unexpected events in the media environment. This article is mainly through two parts to tell. The first part mainly talks about the characteristics of the news from the media environment, and tells the four characteristics of the sudden news events in the media environment. It is the randomness of the sudden, the transmission intensity is very strong, the high degree of participation of the social groups, the long-term impact; the second part is main about the media environment, the process of travel in the sudden emergence of news events countermeasures. Aiming at its characteristics and the problems, some suggestions are given.
\end{abstract}

\section{Introduction}

With the continuous progress of our society, the continuous development of science and technology, the development of Internet technology is getting better and better, and now people through We-Chat, micro-blogging, website and other media from the media for information exchange and communication, the public Network information dissemination has a very important role, both can be the recipient of information transmission, it can be the initiator of information transmission. With the continuous improvement of people's economic level, and promote the development of tourism, and with the development of tourism, but also continue to sudden news events, through the spread of the Internet makes the rapid news of tourism spread, making the tourist location Was concerned about the community, the following we on the media environment from the tourism news events and research, and for the current situation from the media environment, the characteristics of the news of the news to give a corresponding countermeasures to reduce the tourism crisis The adverse effects of news events on tourist sites.

\section{The Characteristics of Tourism News Events in the Media Environment}

Since the media has been called "public media" and "private media" is a personal, universal, extensive, freedom and other information transmission personnel, through scientific, current information transmission, to the uncertainty of the group or a class of media that sends information on a private basis. By travel from the media, you can travel around the travels or other unexpected events that are related to travel events, travel agents, travel agencies, travel agencies, and so on, and pass through the media to attract the attention of the masses of society, which will have a bad impact on the travel location, undermine its image in people's minds, and even may lead to the development prospects of the travel industry. As a result, we can know that the news from the media environment, news not only show the fundamental characteristics of the media from the media, but 
also has the fundamental characteristics of the incident, then we simply talk about the following from the media environment, travel news Event features:

Sudden Randomness. Sudden random factors are mostly sudden news events in the process of emergence, the development process has a particularly large number of reasons do not know, in the absence of any preparation under the premise of a sudden, and rapid Change, it is not easy to imagine what happens next to the event. Sudden randomness is a very important and very important reason for the handling of institutions in resolving sudden news events. If the solution is not correct, it will continue to expand the incident problem, which will cause more and more serious news events. Most of the travel news events occur during large holidays, during the season of tourism, and the news of emergencies in the presence of patterns, categories, etc., there is no law, the emergence and spread of the incident is very sudden, random. Travel sudden news events are likely to occur at any time, uncertain factors too much, because everyone's ideas, views completely different, so the problem may occur at any time, which led to a sudden burst of news events is a sudden Randomness, it cannot be determined and expected.

The Transmission Intensity Is Very Strong. Compared with the traditional media information transmission environment, from the media environment, the expression of information, reflect the pattern of more innovative and fast delivery method, and then let the news of the more rapid, transmission is also very powerful. First of all, the social groups to find the message does not need too cumbersome machines and capabilities, evaluation and sharing is also very convenient and rapid; Secondly, social groups involved in the subjective idea of information transmission is rising. Once the sudden events of tourism, it will be quickly spread and share, which will have a certain impact on the tourist destination. Nowadays, Internet technology is more and more developed, social groups only need to pass a certain platform, the site will be able to carry out speech, evaluation, sharing, reproduced, etc., any way to spread the news events spread, so that the control of tourism sudden news events more difficult, therefore, tourism, news and incident is another feature of the transmission is very strong, and has a wide range.

The Participation of Social Group Is High. From the media environment, social groups, communication channels more easily, and facilitate the exchange, micro-blogging, We-Chat, QQ and other social groups are the usual way of communication and communication, continue to improve, Perfect social groups living habits, more and more social groups are willing to use the media from the way to access and transfer of information and news advice. In the media environment, the information issuer and the information acquirer can become information in the manufacturing and processing personnel, and can achieve the real-time transmission, can participate in the parties to communicate with each other, we all pay attention to the popular Issues to study and explore, and at any time to express their views. At the same time, because of the continuous progress and growth of Internet technology, people's information dissemination site also will be produced, and people through such sites can also focus on the social groups to focus on the popular news events query rankings, while social groups more convenient Way to express, real-time effective to pass out the popular news and information. Social groups not only focus on popular news and information, but also the use of the Internet to express their views. Social groups can at any time through the Internet to pay attention to tourism news events, but also to participate in real-time, to join the discussion, and some social groups for such tourism unexpected news events will be reviewed, forward, which greatly increased the participation of social groups, which also shows that the characteristics of tourism news events and social groups are highly involved.

The Long-Term Impact. The emergence of tourism news events, although it is unlikely that tourists will directly damage the impression of the location of travel, but there may be visitors to travel news events in the travel location of the impression Change, and this type of impression changes, will allow visitors in a very long time, the impression of the travel cannot have a good change, and that the emergence of such a sudden news of tourism, but also allow visitors in the next paragraph Time to select the travel location or route, will try to avoid this tourist news events of the tourist sites. Moreover, the travel industry is characterized by a very distinctive season, if in the busy period of travel, it will often appear this sudden news events, it is easy to bring a serious 
impact on the tourist location, making the tourist location in the strong of the season is no longer strong, will lead directly to the overall image of the tourist site by the interference, which makes the impact of this sudden news of tourism has a long-term characteristics. Once the tourists for the impression of tourism has changed, it will have a certain degree of resistance to the tourist destination, and that the feelings of the conflict is very influential tourists for a long time, so that visitors have a long impression that the tourist attractions are not good, often there will be contradictions and it cannot go here, if such a situation often occurs, will lead to tourist attractions affected, thus, we can also come to the news of the sudden news of tourism is the impact of tourists with long-term Sex, so that visitors to cancel the bad impression of the time is relatively long.

\section{The Countermeasures for the Travel Emergencies News in the Media Environment}

Immediately Resolving According to the Law. Nowadays, China is promoting the rule of law, strictly governing the party, to prevent and solve the news of tourism emergencies must be based on the truth of the incident as the basis for the most standard of laws and regulations. In particular, according to the "People's Republic of China Tourism Law" will be a good management of the tourism industry to ensure that the vital interests of tourists, but also to ensure the standardization of the tourism industry. In the tourism news incident, the tourism law enforcement agencies of the government or other executive organizations, in the process of resolving the news of tourism emergencies, we must pay more attention to the implementation of laws and regulations. With the traditional media transmission of information is different from the media environment, the transmission of unexpected news events more quickly, in the settlement of tourism news when the incident to understand the solution to avoid delays, to immediately control the situation to help the event to expand the prevention of delays due to processing or to solve the improper or the implementation of the organization indiscriminate use of authority and other issues, and further aroused the seriousness of the incident, resulting in sudden news events more and more serious, more and more attention, thus becoming a tourism industry Major accident.

Timely Feedback. To solve the news of the news of the news to ensure that the news of the event update in a timely manner, and timely look at the feedback real-time news, for the fastest time, the news of tourism news to give a reasonable explanation. In the Internet site or platform, the social groups are many cases are watching, want to get more information, if more real-time representative of the message cannot be timely feedback, so that the masses see, understand To the real situation of the incident, then it will make tourism rumors news rumors, so that the original is easy to solve things, become more and more trouble, but also makes the event to the bad direction to spread. Moreover, the social progress of the community, the social groups for the tourism industry is also more and more concerned about the tourists in the process of tourism, but also continue to enhance their supervision of the tourism industry and safeguard their own interests, mainly reflected in: First of all, in the event of tourism problems, tourists now become more and more important to their own evidence of the preservation of evidence, there is evidence to express their own ideas; Secondly, if the consultation cannot get a good feedback, It will pass the media and other methods to pass the event out of their own on the weak side, so that others sympathy, which attracted the attention of social groups, and thus make their own rights and interests to be maintained.

People-Oriented. In a travel process, everyone likes to consider whether their own interests are maintained, are standing on their own point of view to look at the problem, for tourists, visitors both want to travel, but also want to save travel expenses; for the tour guide If the tour guide wants to get the proceeds of the trip and the travel company wants to save money, businesses around the travel destination want visitors to buy something, increase their sales, and get more revenue. In this process of travel, each member of their own interests have their own ideas and views, and different, in fact, the most fundamental element is whether their own interests are maintained. Therefore, in dealing with the process of tourism news, we should pay attention to grasp the root causes of the problem, not only to ensure that the interests of tourists themselves, but also to protect the interests of tourism companies and tourism staff, only to grasp this principle can be more good travel in the 
news of the news to solve the better, so that the two sides get a good solution to the event, so to adhere to the people-oriented, integrity management of the tourism industry.

Real-Time Supervision. With the continuous development of the network, scientific progress, social groups can easily use the Internet platform or website and other channels to obtain, express, share their ideas, opinions. Network information is real-time changes, at any time in the change, all the time constantly updated, constantly updated information, not only the authority of the organization announced the news, there are personal judgments, real-time news, personal speak and so on. The change of network information is one of the main influencers of the news of the news of tourism. It is possible to use the Internet to discuss with the users, and to spread the news of the sudden burst of news. Therefore, we must ensure that real-time monitoring of network information dynamic, if found to be related to tourism issues related to the time, we must promptly deal with and solve the bad information strangled in the cradle, and ready to guard against ready.

\section{Conclusion}

To sum up, from the media environment, the tourism industry's sudden news events is two-sided for the tourist destination, both good side and bad side, although the tourism has brought some dedication. If you can make good use of the media to carry out the characteristics of their own publicity, it can be very convenient to show their own image characteristics to visitors around the show, and once not having a good solution to these problems, then it will affect the overall image of the tourist destination, so the tourism industry must grasp the degree as soon as possible to change the problem to their own advantages. The future development of Chinese tourism industry needs for a very good benign environment, we must all cooperation and do their own essential work and show the good side to the community. To reduce the negative bad news of the sudden emergence of the probability of news events, so as to better develop the tourism industry as soon as possible. Therefore, we hope that through the brief description of this article, we can give some suggestions for future news events in the tourism industry from the media environment.

\section{References}

[1] Wang Wenjing. Yanshan University, Vol. 6 (2014) No 53, p.25-26

[2] Zhou Xiaodong. Jin Mei. Chen Rui. Journal of Yunnan Open University, Vol. 12 (2015) No 27, p.74-76

[3] Xu Zhou. West China Normal University, Vol. 30 (2014) No 19, p.144-145 